\title{
Comment on: Parents' responses to prognostic disclosure at diagnosis of a child with a high-risk brain tumor: Analysis of clinician-parent interactions and implications for clinical practice The role of reflection in dealing with uncertainty
}

\author{
Nino Rainusso ${ }^{1}$ and Ernest Frugé ${ }^{2}$ \\ ${ }^{1}$ Texas Children's Cancer \& Hematology Centers \\ ${ }^{2}$ Baylor College of Medicine
}

March 28, 2021

Title of the manuscript

Comment on: Parents' responses to prognostic disclosure at diagnosis of a child with a high-risk brain tumor: Analysis of clinician-parent interactions and implications for clinical practice

The role of reflection in dealing with uncertainty

Authors' affiliations

Nino Rainusso, M.D.

Associate Professor

Department of Pediatrics, Hematology-Oncology Section

Baylor College of Medicine

Texas Children's Cancer \& Hematology Centers

Ernest Frugé, Ph.D.

Professor

Department of Pediatrics, Hematology-Oncology Section

Baylor College of Medicine

Texas Children's Cancer \& Hematology Centers

Corresponding author

Nino Rainusso, M.D.

Department of Pediatrics, Hematology-Oncology Section Baylor College of Medicine Texas Children's Cancer \& Hematology Centers

1102 Bates Street, Suite 1030.07

Houston, Texas, 77030

Phone: 832-8221449 Fax: 832-8259055 Email:ncrainuss@txch.org 
Word count: 432

Figures \& tables: 0

Running title: reflection and uncertainty in pediatric oncology

Letters to the Editor

Comment on: Parents' responses to prognostic disclosure at diagnosis of a child with a high-risk brain tumor: Analysis of clinician-parent interactions and implications for clinical practice

The role of reflection in dealing with uncertainty

The article by Bluebond-Langner et al. and the editorial comment by Marron highlight the role of uncertainty in the communication of prognosis to parents of children with cancer. ${ }^{1,2}$ Uncertainty is intrinsic to medical practice. It is present from the moment of diagnosis and persists - in varying degrees - through the course of disease, treatment, and recovery or death. Learning to accept and manage ambiguity is a crucial task in the professional development of physicians. Fascinatingly, a physician achieves the highest level of competence when he/she acknowledges uncertainty and engages reflection as described by Carracio. ${ }^{3}$

In this context, reflection is the conscious act of reviewing one's own experience with the aim of learning and improving performance. In medical practice, reflection is usually triggered by circumstances where the "best" course of action is unclear or the outcome is not predictable, especially those situations that evoke strong emotions. ${ }^{4,5}$ Interestingly, the medical care of children with cancer - where it is difficult to exactly forecast the response to treatment or the development of therapy-associated complications - includes all the elements that should prompt reflection in physicians.

Reflection usually involves taking time in the midst of high-stakes situations to review data and decisions carefully. This practice can be enhanced by consulting with experienced colleagues or, when available, working with a trained facilitator. Reflective practice can also be incorporated into training curricula for those entering the field. For example, over the past 25 years our program has offered first year fellows a "Reflective Practice and Leadership Seminar," which provides dedicated time and resources for fellows to reflect on complex situations encountered during their training. ${ }^{6}$ The seminar provides a confidential opportunity where fellows can examine their own knowledge, emotions, beliefs and management strategies critically. A facilitator guides the discussions in collaboration with 2-3 experienced pediatric hematology/oncologists. Uncertainty surrounding the treatment and prognosis of pediatric cancer patients is a typical challenge presented by the fellows. Both the fellows and faculty have found these sessions useful in understanding and managing these scenarios.

We agree with Bluebond-Langner and colleagues that uncertainty plays a pivotal role in communicating difficult news to parents of children with cancer. Failure to recognize and effectively manage uncertainty may lead the practitioner to experience anxiety and/or burnout, and may impact the quality of patient care. Although the capacity to deal with uncertainty may be acquired through long-term exposure to complex cases $^{7}$, we believe that providing routine, methodical opportunities that support reflective practice help both trainees and seasoned physicians to embrace uncertainty and to communicate with patients and their families more empathetically and effectively.

\section{References:}

1. Bluebond-Langner M, Hall N, Vincent K, Henderson EM, Russell J, Beecham E, Bryan G, Gains JE, Gaze MN, Slater O, Langner RW, Hargrave D. Parents' responses to prognostic disclosure at diagnosis of a child with a high-risk brain tumor: Analysis of clinician-parent interactions and implications for clinical practice. Pediatr Blood Cancer 2021;68(3):e28802.

2. Marron JM. Communicating uncertainty: A step in the right direction? Pediatr Blood Cancer 2021;68(3):e28849. 
3. Carraccio CL, Benson BJ, Nixon LJ, Derstine PL. From the educational bench to the clinical bedside: translating the Dreyfus developmental model to the learning of clinical skills. Acad Med 2008;83(8):761-767.

4. Murdoch-Eaton D, Sandars J. Reflection: moving from a mandatory ritual to meaningful professional development. Arch Dis Child 2014;99(3):279-283.

5. Winkel AF, Yingling S, Jones AA, Nicholson J. Reflection as a Learning Tool in Graduate Medical Education: A Systematic Review. J Grad Med Educ 2017;9(4):430-439.

6. Frugé E, Mahoney DH, Poplack DG, Horowitz ME. Leadership: "They never taught me this in medical school". J Pediatr Hematol Oncol. 2010;32(4):304-308.

7. White G, Williams S. The certainty of uncertainty: can we teach a constructive response? Med Educ 2017;51(12):1200-1202 